\title{
Comparison of Pressure Losses of Clean and Deposit-covered Heat Exchange Surfaces of a Natural Gas Cooler
}

\author{
Mária Čarnogurskán* , Miroslav Př́hoda², Juraj Václav \\ 'Faculty of Mechanical Engineering, Technical University of Košice, Department of Power Engineering, Vysokoškolská 4, \\ Košice, 042 00, Slovak Republic \\ 2 Faculty of Metallurgy and Materials Engineering, V̌̌B - Technical University of Ostrava, Department of Thermal Engineering, \\ Ostrava-Poruba, 708 00, Czech Republic \\ Division of Nuclear Materials Nuclear Regulatory Authority of the Slovak Republic, Bratislava, 800 00, Slovak Republic
}

\section{BIOGRAPHICAL NOTES}

Mária Čarnogurská, prof. Ing. CSc. She is a graduate of Faculty of Mechanical Engineering, Technical University of Kosice (TUKE). Currently works as a head of Department of Power Engineering at Faculty of Mechanical Engineering within a. m. university. Her long-term professional focus is within the area of power engineering. The research is concentrated on mathematical and physical modelling of processes and effects applied in power engineering, the flow of different media in energy machines and appliances as well as the exploitation of non-utilised heat energy in diverse industrial applications.

Miroslav Př́hoda, prof. Ing. CSc. He is a graduate of Faculty of Metallurgy at Mining University of Ostrava. Currently works at the Department of Thermal Engineering at Faculty of Metallurgy and Materials Engineering, VŠB - Technical University of Ostrava and is a authority for heat processes within industrial and municipal sphere. His research is concentrated on mathematical and physical modelling of thermal processes, thermal work of basic units of continuous casting equipment, temperature conditions in metal recuperators, utilisation of steel enthalpy at metallurgical plants, determination of thermal conductivity and thermal diffusivity at high temperatures.

Juraj Václav, Ing. He graduated the Faculty of Mechanical Engineering of Slovak Technical University in Bratislava. Currently works as a Head of Nuclear Materials Division at Nuclear Regulatory Authority of the Slovak Republic. His work is focused on state supervision upon handling with nuclear materials, including the assessment of thermomechanical parameters of facilities for spent fuel storage and transport. He is studying in the third year of doctoral studies at the Technical University of Košice.

\section{KEY WORDS}

Natural gas cooler, deposit, pressure losses, compression work

\section{ABSTRACT}

This article discusses the pressure losses which occur on the outer and inner heat transfer surface area of natural gas coolers. An analytical method is used to determine the pressure loss on the outside of the heat transfer surface area and the development of this loss is presented depending on the thickness of coating (dirt) deposited on the fins of the heat exchange surfaces. The pressure loss inside the cooling tubes from 
the layer of deposition is expressed specifically as friction loss, especially the loss of local resistance and collective pressure loss. The results include an assessment of the impact of the deposited impurities on the compression work and for providing the required cooling performance.

\section{Introduction}

Pressure losses affect the energy consumption of the compressor station as a whole. It is therefore necessary to know what pressure loss is caused by deposited material on the external and internal heat transfer surfaces of the cooler, so the limit values can be determined for the thickness of deposited material on both sides of the heat transfer surface area for the acceptable operation of the cooler.

The total pressure loss on the side of cooling air depends mainly on the shape of the outer heat transfer surface area. The greater the number of fins of the same thickness on a one meter length of the cooling tubes of a given diameter, the greater the pressure loss of such a cooler. This fact needs to be considered in the design of a fan or set of fans to cool natural gas.

The total pressure loss on the part of the gas is given by the sum of local losses, characterized by local loss coefficient $\xi$, and length losses characterized by the friction coefficient $\lambda$. In terms of influence of deposits on the pressure loss, it can be stated that deposits provide additional resistance, which increases the pressure drop. Its placement on the outer heat transfer surface area results in a reduced hydraulic diameter and reduces the cooling effect. The settling of deposits on the internal surfaces of the tubes and the radiator inlet and outlet tube reduces the flow cross section of the coolant tubes, and thus increases the rate of flow, and therefore the pressure loss [1]. Deposition is not evenly distributed across the cross section and the length of the tube cooler, making the calculation of the pressure loss even more difficult. As on the outside, the inner coating adds additional thermal resistance, which reduces the amount of the cooling of the gas.

\section{Description of cooler}

The cooler consists of a tube set with a total of 1323 tubes, in which the tubes are place in an alternating arrangement. The angle of the tubes to the direction of the flow of cooling air is s1 (Fig. 1) Three rows of tubes (in the upper part of the block) take heated gas in one direction and three rows in the lower part of the blog take it in the other direction (Fig. 2).

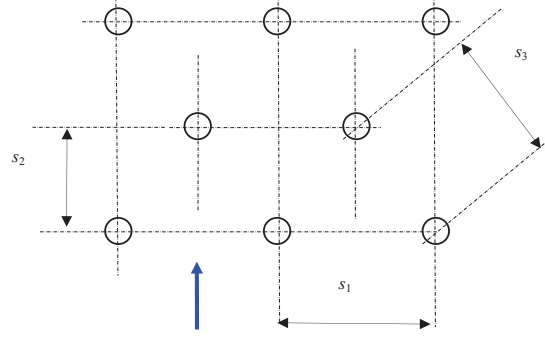

Fig. 1: Arrangement of tubes.

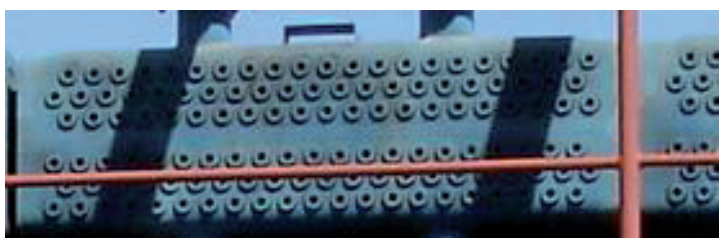

Fig. 2: Detail of cooling block with placement of tubes.

The cooler provides cooling of gas to the desired temperature using seven dual-fan units with a volume flow rate of one fan $\mathrm{Qv}_{\mathrm{v}}=41.5 \mathrm{~m}^{3} \cdot \mathrm{s}^{-1}$. The manufacturer's stated pressure loss in the case of a clean external surface of the heat transfer surface area has a value of $197 \mathrm{~Pa}$. The outer surface of the finned tube of the condenser (Fig. 3) and the main parameters of the tube and the rib are shown in Table 1. The individual meanings of each label in Table 1 are shown in Figure 4.

Pressure losses were determined on the air and gas sides for two alternatives of heat-exchange surfaces.

- Net external heat surface area and area with deposits of thickness of $h_{n, 2}$,

- Net internal heat surface area and area with deposits of thickness of $h_{n, 1}$.

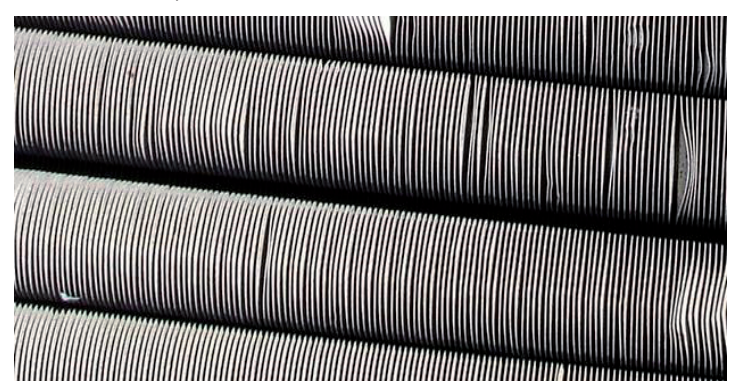

Fig. 3: Finned cooler tubes $\mathrm{CH} 4$. 
Table 1: Parameters of the fan and heat exchange surfaces provided by manufacturer of the cooler.

\begin{tabular}{|l|l|l|l|l|l|l|l|l|}
\hline $\left.\mathbf{Q} \mathbf{( \mathbf { m } ^ { 3 }} \mathbf{s}^{-1}\right)$ & $\Delta \mathbf{p}(\mathbf{P a})$ & $\mathbf{b}(\mathbf{m m})$ & $\mathbf{s r}(\mathbf{m m})$ & $\mathbf{d}_{\mathbf{1}}(\mathbf{m m})$ & $\mathbf{d}_{2}(\mathbf{m m})$ & $\mathbf{d r}(\mathbf{m m})$ & $\mathbf{h r}_{\mathbf{r}}(\mathbf{m m})$ & $\mathbf{s}_{1}=\mathbf{s}_{2}=\mathbf{s}_{3}(\mathbf{m m})$ \\
\hline 41.5 & 197 & 2.5 & 0.65 & 25 & 30 & 58 & 14 & 63.5 \\
\hline
\end{tabular}

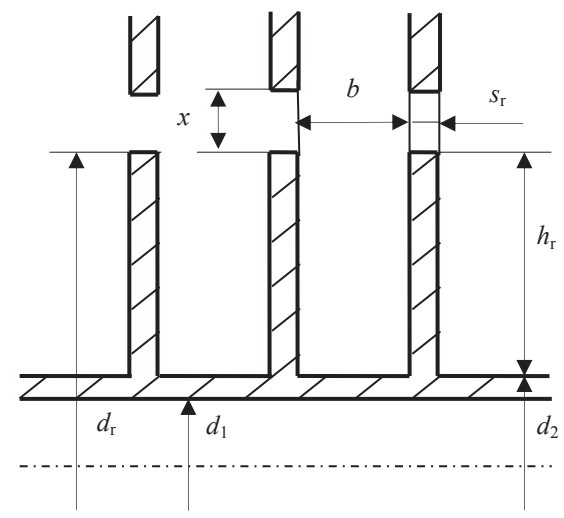

Fig. 4: Geometry of the heat exchange surfaces of the cooler tubes.

\section{Pressure losses on the outside of the cooler tube}

On the outside of the heat exchange surface there are deposits of contaminants from the air, which are sucked in from the environment during the operation of the fans. These are deposited on the surface of the fins and the smooth portion of the tube between them. The deposit of impurities is more intense on the surface of the fins and the smooth part of bottom row of tubes in the set (Fig. 6) and decreases significantly towards the last row in the direction of air flow. The maximum thickness of the deposit $\mathrm{h}_{\mathrm{n}, 2}$ on the fins is defined as the width of the free space between the fins b (Fig. 5). After it is filled, the air flows only in the space between the heads of the fins with width $\mathrm{x}$ and length $\mathrm{L}$.

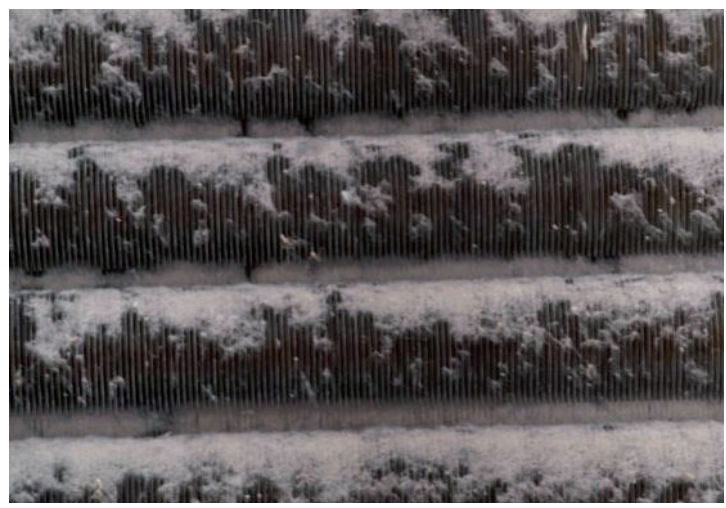

Fig. 5: View of coated cooler tubes (lower part of the tube set).
Pressure loss on the air side $\Delta \mathrm{p}$ is determined by [2] in the equation:

$\Delta p=2 \cdot C_{1} \cdot C_{2} \cdot\left(n_{r}+1\right) \cdot \operatorname{Re}_{d_{n}}^{-0,27} \cdot \frac{v^{2}}{2} \cdot \rho_{2}(\mathrm{~Pa})$

where: $\mathrm{C}_{1}$ - coefficient dependent on the spacing of the tubes in direction of the width of the set $\mathrm{s} 1$ (1), $\mathrm{C}_{2}$ - coefficient depending on the distance of the centres of the tubes $s_{3}(1), v$ - air velocity in the narrowest cross section $\left(\mathrm{m} \cdot \mathrm{s}^{-1}\right), \rho_{2}$ - density of air at middle air temperature $\left(\mathrm{kg} \cdot \mathrm{m}^{-3}\right), \mathrm{n}_{\mathrm{r}}$ - number of rows of tubes in the direction of the air flow (m), Re - Reynolds number calculated from hydraulic diameter $\mathrm{dh}$.

The corrective coefficients, $\mathrm{C}_{1}$ a $\mathrm{C}_{2}$ are taken on the basis of the arrangement of pipes in the cooler and their own geometry depended on figures 6 and 7.

The hydraulic diameter for a clean surface is determined by equation (2):

$d_{\mathrm{h}}=\frac{4 \cdot S_{\mathrm{p}}}{O}=\frac{2 \cdot\left[\left(s_{1}-d_{2}\right) \cdot b+S_{\mathrm{r}} \cdot x\right]}{\left(2 \cdot h_{\mathrm{r}}+b+S_{\mathrm{r}}\right)}$

where: $S_{p}$ - area of the air flow between two fins $\left(m^{2}\right)$, O - connection formed by contact of the air with the fins and the smooth area the tube $(\mathrm{m}), \mathrm{b}$ - the distance between two fins (m), $x$ - distance between top diameters of fins $(m), h_{r}$ - fin height $(\mathrm{m}), \mathrm{Sr}$ - thickness of fin (m).

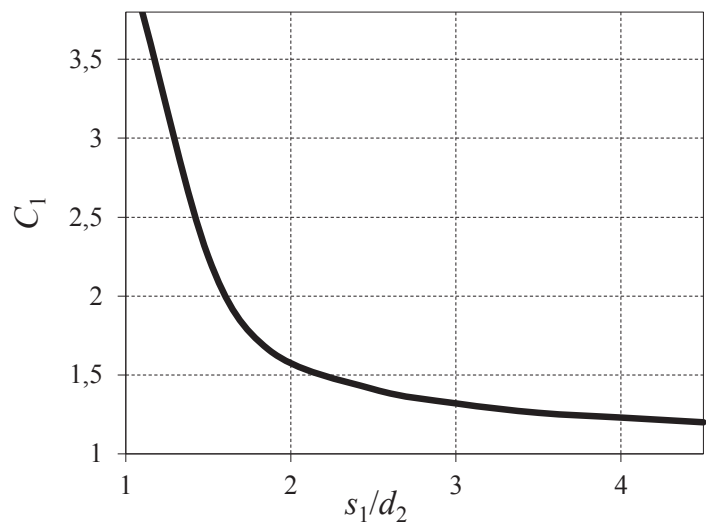

Fig. 6: Corrective coefficient $C_{1}$. 


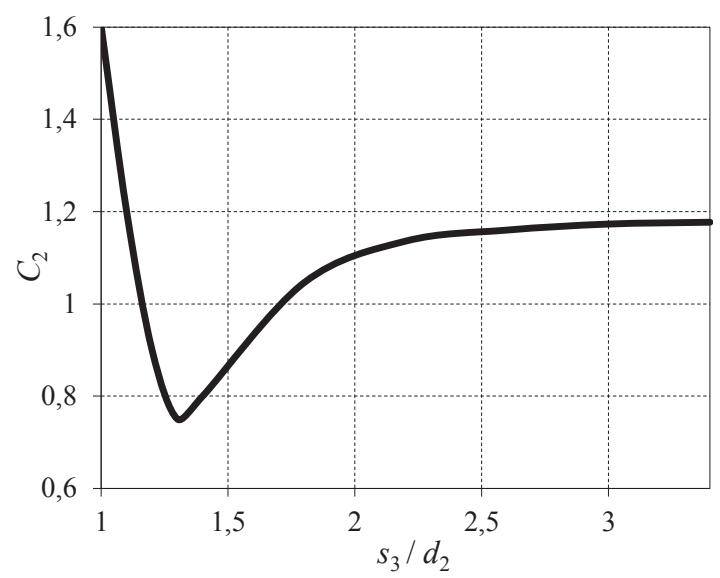

Fig. 7: Corrective coefficient $\mathrm{C}_{2}$.

The Reynolds number for a given hydraulic diameter is determined by the equation (3)

$\operatorname{Re}_{d_{h}}=\frac{v \cdot d_{\mathrm{h}}}{\nu}(1)$

where: $v$ - air velocity in the narrowest cross-section between the two fins $\left(m \cdot s^{-1}\right), \nu$ - kinematic viscosity of the air $\left(\mathrm{m}^{2} \cdot \mathrm{s}^{-1}\right)$.

The hydraulic for the covered surface of the cooler is determined by the equation:

$d_{h}=\frac{4 \cdot S_{\mathrm{p}}}{O}=\frac{2 \cdot\left[\left(s_{1}-d_{2}\right) \cdot b+S_{\mathrm{r}} \cdot x-4 \cdot h_{\mathrm{r}} \cdot h_{\mathrm{n}, 2}\right]}{\left(2 \cdot h_{\mathrm{r}}+b-h_{\mathrm{n}, 2}+S_{\mathrm{r}}\right)}(\mathrm{m})$

where: $h_{n, 2}$ is the thickness of deposits on the fin (m).

For a CH4 cooler at KS01 in Vel'ké Kapušany a pressure drop obtained is dependent on a clean outer heat transfer surface area as presented in Fig. 8 . When cleaning the internal surface of the fin, the calculated pressure drop according to [3] is $46 \mathrm{~Pa}$ and according to [4] is $59 \mathrm{~Pa}$. The difference in terms of both sources is as much as $28 \%$. Increasing the thickness of the coating increases the pressure drop and with a thickness of about $\mathrm{h}_{\mathrm{n}, 2}=0.84 \mathrm{~mm}$ on each side of the fin, the pressure drop reaches a permissible value of $197 \mathrm{~Pa}$. When the coating is of thickness $h_{n, 2}=1.25 \mathrm{~mm}$ there arises a complete clogging the space between the ribs. Under this state of clogging of the outer heat transfer surface area, the pressure drop reaches a value of approximately $750 \mathrm{~Pa}$, which is far beyond the capacity of the installed fans.

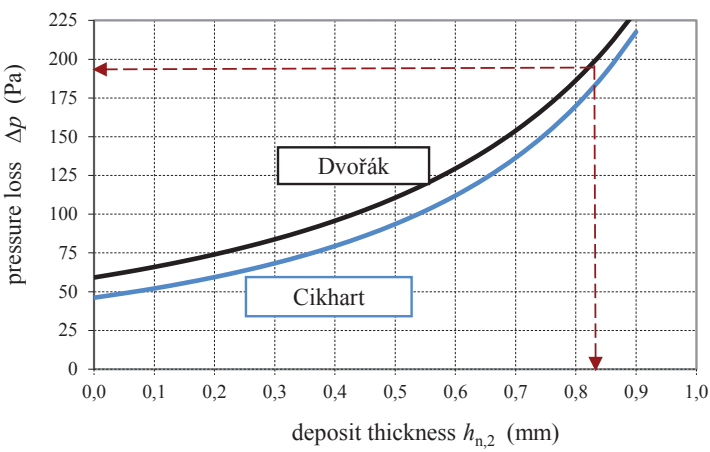

Fig. 8: Course of pressure losses depending on thickness of deposits on the outside of the fins.

\section{Pressure losses on the inside of tubes in the cooler}

The pressure loss on the side of the gas depends primarily on the quality of the internal surface of the tube covered with sediments and the rate of gas flow. The pressure loss due to local resistance depends on the type of the local resistance and coefficient of resistance, which has to be determined separately for each type of resistance.

The total pressure loss on the gas side $\Delta \mathrm{p}$, under actual temperature and gas pressure can be expressed in a broken-down form by the equation

$$
\begin{aligned}
& \Delta p=\sum_{i=1}^{n} \lambda_{i} \cdot \frac{L_{i}}{d_{i}} \cdot \frac{U_{i}^{2}}{2} \cdot \rho_{0} \cdot\left(\frac{p}{p_{0}} \cdot \frac{T_{0}}{T} \cdot \frac{z_{0}}{z}\right)+ \\
& +\sum_{j=1}^{m} \xi_{j} \cdot \frac{U_{j}^{2}}{2} \cdot \rho_{0} \cdot\left(\frac{p}{p_{0}} \cdot \frac{T_{0}}{T} \cdot \frac{z_{0}}{z}\right)(\mathrm{Pa})
\end{aligned}
$$

where: $\lambda_{i}$ - coefficient of resistance (1), $d_{i}$ - internal diameter of the specific tube section of the cooler $(m), \mathrm{Li}$ - length of specific section (m), $\rho_{0}$ - density of gas under normal conditions $\left(\mathrm{kg} \cdot \mathrm{m}^{-3}\right), v_{\mathrm{i}}$ - gas velocity in a specific section under actual temperature and pressure of gas $\left(\mathrm{m} \cdot \mathrm{s}^{-1}\right), \mathrm{n}$ - number of sections of the cooler (1), $\varepsilon_{\mathrm{j}}$ - coefficient of local loss (1), T - actual temperature of gas (K), $\mathrm{p}$ - actual pressure of gas $(\mathrm{Pa}), \mathrm{z}$ - compressibility factor under working conditions (1), zo - compressibility factor under normal conditions (1), index i -means the $\mathrm{i}$-th section of the cooler, $\mathrm{j}$ - means the $\mathrm{j}$-th local resistance.

Under calculation of pressure losses, work is often done, apart from with equation (5), with equations which take account of the changes in the 
properties of gas under changed temperature and pressure of gas using various further modifications of the basic equation for local losses or length losses.

For high-pressure and medium-pressure gas pipes, it is possible to apply the equation to calculate pressure losses of resistance and local losses which are derived from the general expression of the square of the pressure difference referred to in equation (6) [6]

$$
\begin{aligned}
& p_{1}^{2}-p_{2}^{2}=\sum_{i=1}^{n} \lambda_{i} \cdot \frac{L_{i}}{d_{i}} \cdot \frac{z_{\mathrm{s}} \cdot r \cdot T_{\mathrm{s}} \cdot Q_{m}^{2}}{S_{i}^{2}}+ \\
& +\sum_{j=1}^{m} \xi_{j} \cdot \frac{z_{\mathrm{s}} \cdot r \cdot T_{\mathrm{s}} \cdot Q_{m}^{2}}{S_{j}^{2}}\left(\mathrm{~Pa}^{2}\right)
\end{aligned}
$$

where: $\mathrm{p}_{1}$ - gas pressure before entering the cooler $(\mathrm{Pa}), \mathrm{p}_{2}$ - gas pressure at the outlet of the cooler $(\mathrm{Pa}), \mathrm{Zs}$ - mean value of the compressibility factor (1), $\mathrm{Q}_{\mathrm{m}}$ - mass flow rate of gas $\left(\mathrm{kg} \cdot \mathrm{s}^{-1}\right), \mathrm{T}_{\mathrm{s}}$ - mean temperature of the gas in the condenser $(K), r$ specific gas constant $\left(\mathrm{J} \cdot \mathrm{kg}^{-1} \cdot \mathrm{K}^{-1}\right), \mathrm{Si}, \mathrm{S}_{\mathbf{j}}$ - flow area at a specific place in the cooler $\left(\mathrm{m}^{2}\right)$.

Cooler pressure drop is expressed by the equation of the form:

$$
\Delta p=p_{1}-\sqrt{p_{1}^{2}-\left(\begin{array}{l}
\sum_{i=1}^{n} \lambda_{i} \cdot \frac{L_{i}}{d_{i}} \cdot \frac{z_{s} \cdot r \cdot T_{\mathrm{s}} \cdot Q_{m}^{2}}{S_{i}^{2}}+ \\
+\sum_{j=1}^{m} \xi_{j} \cdot \frac{z_{s} \cdot r \cdot T_{\mathrm{s}} \cdot Q_{m}^{2}}{S_{j}^{2}}
\end{array}\right)}(P a)
$$

The mass flow rate of gas required in the equations (6) and (7) is determined by the equation:

$Q_{m}=Q_{V} \cdot \rho \quad\left(\mathrm{kg} \cdot \mathrm{s}^{-1}\right)$

where: $\mathrm{Qv}_{\mathrm{v}}$ volume flow rate of gas $\left(\mathrm{m}^{3} \cdot \mathrm{s}^{-1}\right), \rho$ - density of gas $\left(\mathrm{kg} \cdot \mathrm{m}^{-3}\right)$.

Local losses in the cooler itself are dependent on a particular place in the cooler where there are incorporated e.g. valves, elbows, collectors and any other place in the cooler where there is a change of direction or change of flow speed.

In the case of friction losses it is necessary to know the nature of the gas flow. In the turbulent flow the friction coefficient $\lambda$ is generally dependent on the Reynolds number and the relative roughness of the tube given by the ratio $\mathrm{k} / \mathrm{d}_{1}$. The Reynolds number in the tubes of the cooler of DN25 has a clean surface value of $5.78 \cdot 10^{5}$, the relative roughness is given in calculations as 0.004 . To determine $\lambda$ Nikuradse diagram is used [5].

The total pressure loss inside the cooler is determined under the following operating conditions: pressure $\mathrm{p}_{1}=6.528 \mathrm{MPa}$, temperature of the gas at the inlet to the cooler $\mathrm{t}_{1,1}=60^{\circ} \mathrm{C}$, temperature of the gas at the outlet of the cooler $\mathrm{t}_{1,2}=45^{\circ} \mathrm{C}$, air temperature $20^{\circ} \mathrm{C}$.

In the analysed cooler there are three nominal tube diameters (DN25, DN125, DN300). The tubes with an inner diameter of $25 \mathrm{~mm}$, a coating of $1 \mathrm{~mm}$ thickness will reduce the flow cross section by $8 \%$. Reduction of the flow cross section by $8 \%$ will change the speed (its growth) by $18.1 \%$, causing an increase in pressure loss of about $39.6 \%$. For other tubes upstream of the place and the cooler, the same thickness of coating works to increase the speed to a much lesser extent. With a tube diameter of $125 \mathrm{~mm}$, speed will increase by $3.3 \%$ (pressure loss of $6.7 \%$ ). For a diameter of $300 \mathrm{~mm}$ there is a speed increase of $1.3 \%$ and a pressure loss of $2.7 \%$. The effect of a coating of 1 $\mathrm{mm}$ thickness and the rate of change of pressure drop can be seen in Fig. 9. From the course of both monitored parameters it can be see that the deposition can be expected to have a significant effect on pressure losses with smaller nominal pipe diameter. For a DN of over 200, the small thickness of the deposit $(1 \mathrm{~mm}$ ) is not important for the assessment of the pressure losses.

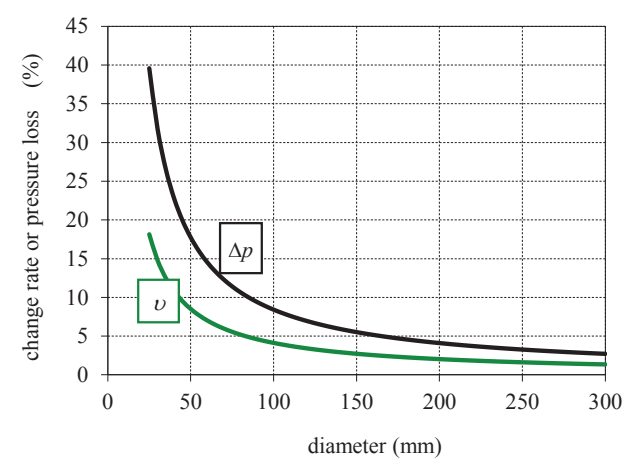

Fig. 9: Effect of a coating of $1 \mathrm{~mm}$ thickness and change of speed and pressure drop.

Since it is not possible to anticipate the roughness of the tube coating, and it is equally impossible to determine it by measuring, solving the pressure loss will be conducted for the case of smooth tubes (ideal situation in practice unattainable) and 
with the deterioration due to surface deposition rough tubes. Deterioration of the surface is taken into account by appropriate selection of a criteriaequation to calculate the coefficient of friction $\lambda$ depending on the value of the Reynolds number and the relative roughness of the tube $\mathrm{k} / \mathrm{d}_{1}$.

The total pressure loss due to friction $\Delta \mathrm{p} \lambda_{\lambda}$ (Tab. 2) represents deposits of thickness $h_{n, 1}=0 \mathrm{~mm}$, about $25.4 \mathrm{kPa}$, which is only $0.40 \%$ of the value of operating pressure $(6.528 \mathrm{MPa})$. The total pressure loss of local resistance has a value of $34.0 \mathrm{kPa}$, which represents about $0.51 \%$ of the operating gas pressure. The total pressure loss of the cooler, in the above operating conditions with clean the internal surfaces of cooler tubes is $\Delta \mathrm{p}=$ $59.4 \mathrm{kPa}$, representing $0.91 \%$ of the operating pressure.

The influence of deposits on pressure loss is significant for larger thicknesses. When the thickness of $\mathrm{h}_{\mathrm{n}, 1}=7 \mathrm{~mm}$, the total pressure loss is $1452 \mathrm{kPa}$, which is up to $22.25 \%$ of the operating pressure. The friction loss in a cooler tube with nominal diameter of DN25 is most important, and it contributes to a total friction loss $99.5 \%$. From total local and friction losses, the value of the pressure loss due to the friction of the pipe itself is $91 \%$. The progress of the total pressure loss in the $\mathrm{CH} 4 \mathrm{cool}-$ er, friction losses and local losses, depends on the thickness of the deposition, is shown in Fig. 10.

For a coating of deposits of up to $3 \mathrm{~mm}$ the effect of deposition on pressure loss is relative small (circa $2 \%$ from the value of operating pressure). Above this thickness the pressure losses start to grow rapidly and at $7 \mathrm{~mm}$ thickness they reach 22.25\% (Fig. 11).

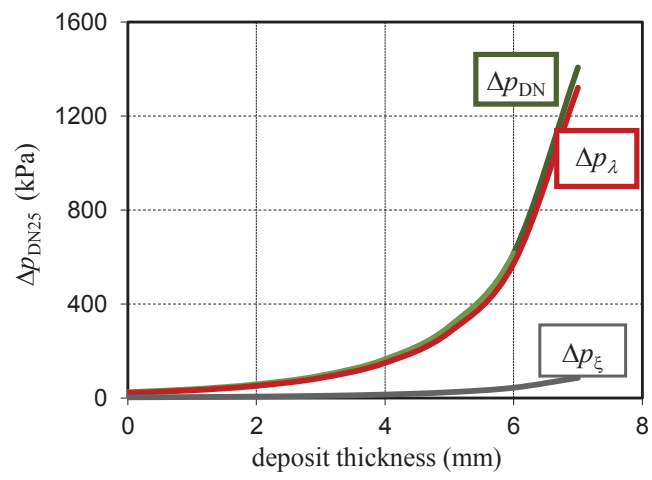

Fig. 10: Course of individual pressure losses in $\mathrm{CH} 4$ cooler depending on thickness of deposit.

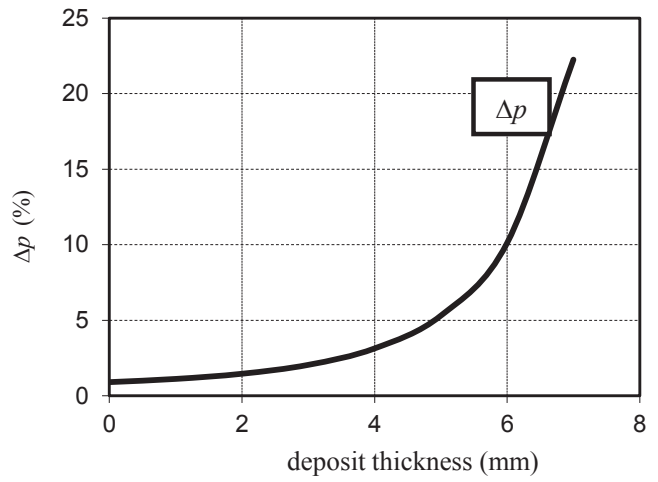

Fig. 11: Course of overall pressure loss express as a percentage of operating pressure.

\section{Conclusion}

This article gives an analytical method for determining the pressure losses on the outside and inside of a gas cooler.

In the case of clean outer surface of the fins, there was calculated pressure loss according to two sources in the literature sources and the results differ only by $10 \mathrm{~Pa}$. For about 67\% clogging, the space between the fins reaches pressure loss projections. Above this deposit it is not recommended to run the cooler at all, since its cooling capacity will be virtually zero.

The greater the thickness of the coating on the inside of the cooler tubes, the more marked the total pressure loss as a share of the value of the operating pressure is. This percentage will be increased if a certain part of the tubes are completely clogged and other tubes are working with deposits of lower thickness. The analysis of the effect completely clogging pipes 100 (out of 1323) with zero thickness of deposit in other tubes in 1223 shows that the pressure loss represents only $0.42 \%$ of the value of the operating pressure. With the same number of clogged pipes and deposits of thickness on the other tubes of $7 \mathrm{~mm}$, there is a pressure drop to $23.72 \%$ of the operating pressure. During operation of the gas cooler is not possible to completely avoid a build-up of deposits. This means that part of the compression work is wasted. If the supply of gas to each of CS is to be taken into account, it is justified, in terms of pressure loss, to clean the internal surface of pipes of the cooler on a regular basis to prevent the deposits on the inside of the tube with a thickness of greater than $3 \mathrm{~mm}$, which corresponds to a pressure drop, de- 
Table 2: Development of need to increase compression work for the reason increased thickness of deposits in the tubes of the cooler.

\begin{tabular}{|c|c|c|c|c|c|}
\hline hn,1 & $\Sigma \Delta p$ & $\begin{array}{l}\text { pressure } \\
\text { difference }\end{array}$ & $\begin{array}{l}\text { increased } \\
\text { pressure }\end{array}$ & $\begin{array}{l}\text { compression } \\
\text { work }\end{array}$ & $\begin{array}{l}\text { increased } \\
\text { compression } \\
\text { work }\end{array}$ \\
\hline$(\mathrm{mm})$ & $(\mathrm{kPa})$ & $(\mathrm{kPa})$ & $(\mathrm{kPa})$ & (\%) & (\%) \\
\hline 0 & 59.38 & 0.0 & 1000.0 & 100.0 & 0.0 \\
\hline 1 & 73.20 & 13.8 & 1013.8 & 101.4 & 1.4 \\
\hline 2 & 95.56 & 36.2 & 1036.2 & 103.6 & 3.6 \\
\hline 3 & 134.01 & 74.6 & 1074.6 & 107.5 & 7.5 \\
\hline 4 & 204.88 & 145.5 & 1145.5 & 114.6 & 14.6 \\
\hline 5 & 346.65 & 287.3 & 1287.3 & 128.7 & 28.7 \\
\hline 6 & 660.50 & 601.1 & 1601.1 & 160.1 & 60.1 \\
\hline 7 & 1452.47 & 1393.1 & 2393.1 & 239.3 & 139.3 \\
\hline
\end{tabular}

pending on the number of completely clogged tubes, in the range of $2.02 \%$ to $27.2 \%$ of operating pressure. In this case, it is the acceptable pressure drop. The need to increase the compression work with this coat thickness, compared to a clean pipe, is about $7.5 \%$ (see Tab. 2). The table also shows the need to increase the compression work throughout the examined range coat thickness. Surface cleanliness means low pressure loss, low value of lost work and a high compression cooling effect of the cooler.

\section{Acknowledgments}

This article was produced as part of the tasks connected with solving the VEGA project, no. 1/0004/14 a SP2014/46-FMMI VŠB TUO.

\section{References and Notes}

[1] ČARNOGURSKÁ, M. PŘíHODA, M, KUBÍK, M., GALLIK, R., HRŠÁK, D. (2013). Methodology of the Sediment Thickness Calculation on the Heat Exchange Area of a Coolers Natural Gas. International Journal of Mechanic Systems Engineering. Vol. 3, no. 1, p. 14-19.

[2] CIKHART, J., POLANSKÝ, A. (1976). Výměníky tepla v tepelných sítích. SNTL Praha.

[3] DVOŘÁK, Z. (1992) Sdílení tepla a výměníky. ES ČVUT Praha.

[4] VAMPOLA, J. (1984). Přestup tepla a tlakové ztráty při proudění plynu svazkem žebrovaných trubek. Technické príručky 8, SVÚSS, SNTL Praha.

[5] ČARNOGURSKÁ, M., DOBÁKOVÁ, R. (2008) Mechanika tekutín, Zbierka príkladov z vybraných kapitol. Elfa, s.r.o., Košice.

[6] VARGA, A., KIZEK, J. (2001) Doprava a distribúcia plynu Plynárenstvo: TU, HF, Košice.

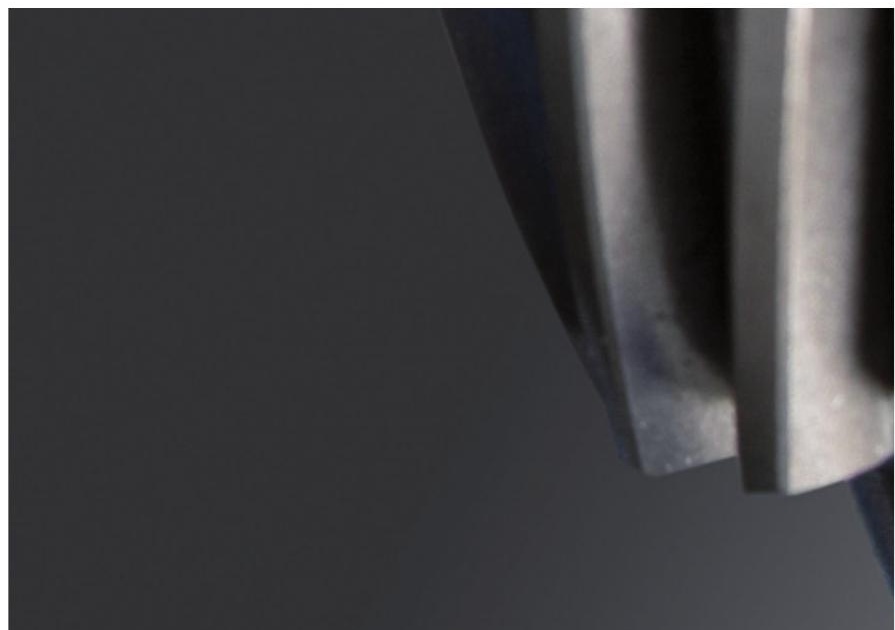




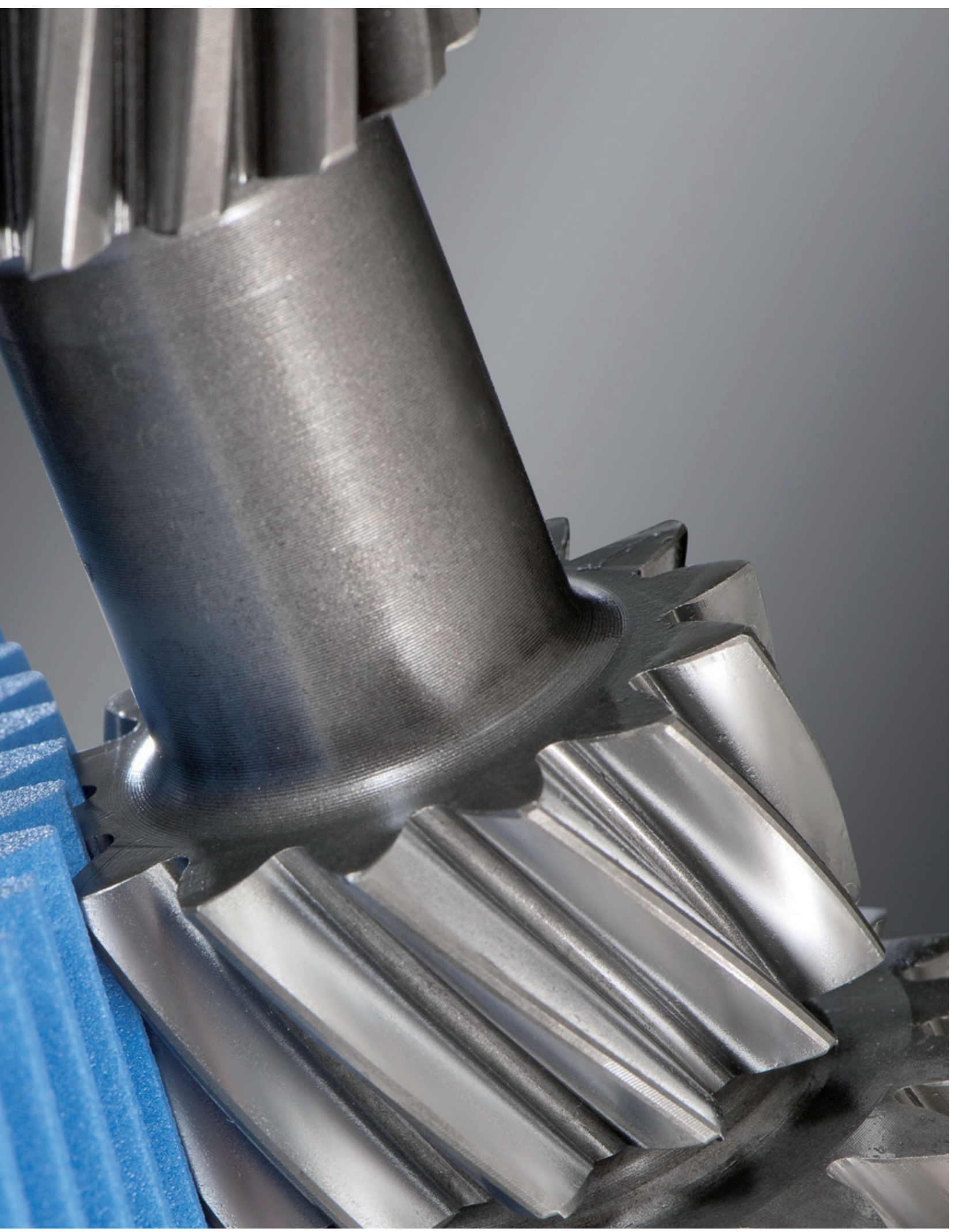

